\title{
PROJETO PILOTO DE FORMAÇÃO NO AMBIENTE VIRTUAL DE APRENDIZAGEM MOODLE DIDÁTICO IFRS: CONHECENDO OS OBJETOS DE APRENDIZAGEM
}

\author{
Kátia Martins Soares* \\ Regina da Silva Lima**
}

Marcelo Augusto Rauh Schmitt***

\begin{abstract}
Resumo: Este artigo apresenta a construção de um projeto piloto de formação continuada destinada aos docentes dos anos finais do ensino fundamental, com o objetivo de analisar a capacidade da plataforma MOODLE para a inserção de objetos de aprendizagem. Seu desenvolvimento e avaliação ocorreram por meio de uma disciplina direcionada aos discentes do Mestrado em Informática na Educação do Instituto Federal do Rio Grande do Sul, na qual se verificou que a Plataforma apresenta capacidade para receber diferentes objetos de aprendizagem. Além disso, o referido ambiente oferece a oportunidade de acompanhamento do curso pelos tutores, incentivando os alunos a uma reflexão a respeito da utilização das tecnologias aliada aos conteúdos didáticos.
\end{abstract}

Palavras-chave: Ensino. Formação. Tecnologia.

\section{Introdução}

A proposta de criar um curso de formação continuada à distância no Ambiente Virtual de Aprendizagem (AVA) MOODLE ${ }^{2}$ surgiu no contexto do Mestrado Profissional em Informática do Instituto Federal do Rio Grande do Sul (IFRS), Campus Porto Alegre. O Projeto foi desenvolvido dentro da Plataforma MOODLE didático ${ }^{3}$ destinada à prática e exercícios discentes do IFRS considerando que o AVA é um ambiente restrito a membros desta instituição. Por constituir-se como um componente educacional, foi aplicado em uma

\footnotetext{
* Mestranda do Mestrado Profissional em Informática na Educação do Instituto Federal de Educação, Ciência e Tecnologia do Rio Grande do Sul - IFRS. Licenciada em Educação Física pela Universidade Federal do Rio Grande do Sul - UFRGS. Especialista em Saúde Mental Coletiva pela ESP-RS, professora na Prefeitura de Canoas.

** Mestranda do Mestrado Profissional em Informática na Educação do Instituto Federal de Educação, Ciência e Tecnologia do Rio Grande do Sul - IFRS. Licenciada em Pedagogia pela Universidade Federal do Rio Grande do Sul - UFRGS. Especialista em Mídias na Educação pela Universidade Federal do Rio Grande do Sul UFRGS. Professora na Prefeitura de Canoas.

*** Doutor em Informática na Educação. Professor do Mestrado Profissional em Informática na Educação do Instituto Federal de Educação, Ciência e Tecnologia do Rio Grande do Sul - IFRS.

${ }^{2}$ MOODLE: Modular Object-Oriented Dynamic Learning Environment; ou seja, um produto modular e dinâmico de suporte à aprendizagem (BEHAR, 2013; SCHMITT et al 2013).

${ }^{3}$ http://moodle.inf.poa.ifrs.edu.br/
} 


\section{\#tear}

disciplina do curso do mestrado.

Percebe-se que o atual momento vivido pela sociedade, no qual a tecnologia permeia as atividades do dia-a-dia, trouxe, em relação ao ambiente escolar, novos desafios aos docentes. Nesse contexto, cabe aos professores a responsabilidade de criar estratégias que possibilitem aprendizagens significativas em sala de aula, despertando o interesse dos alunos.

No entanto, diferente dos educandos, que estão familiarizados com celulares, tablets e computadores, alguns professores ainda precisam apropriar-se das questões tecnológicas, de modo a proporcionar uma mudança efetiva no planejamento pedagógico, adequando-o à nova realidade educacional.

Desse modo, observa-se que, no cotidiano escolar, somente a aproximação do professor com as tecnologias e objetos educacionais mostra-se insuficiente, é preciso mais investimentos em recursos tecnológicos e humanos. Logo, percebe-se a necessidade de formação, tanto inicial quanto continuada para elevar a qualidade do ensino (ZUIN 2010).

Diante disso, a proposta de formação continuada no AVA oferece a possibilidade de conhecimento e interação com objetos de aprendizagem que podem qualificar as aulas, melhorando a motivação dos alunos e estimulando o professor a novos desafios (MORAN, 2000).

Os objetivos estipulados para o curso de formação de docentes envolvem possibilitar o acesso a diferentes objetos de aprendizagem, estimular o uso de tecnologias acessíveis e propor um ambiente de troca de experiências e formação.

Intitulado "Formação Continuada em TICs para Professores da Rede Básica", o projeto estima uma carga horária de 30h (trinta horas) para o curso, o qual se encontra dividido em 10 (dez) tópicos. No entanto, sua validação ocorreu por meio de uma aula direcionada aos alunos do curso de mestrado do IFRS.

Assim, para elaboração do projeto e análise dos resultados procurou-se através de referencial teórico apropriado, privilegiar autores que abordam a relação entre a tecnologia e os objetos de aprendizagem na educação, como Tarouco (2014) Schmitt (2013), Behar (2013), Moran (2000) e Zuin (2010). Os referidos conceitos são essenciais para se entender o escopo e estão permeados pela Teoria Construtivista de Piaget, na qual a aprendizagem ocorre pela interação do indivíduo com o meio físico e social. 


\section{Referencial teórico}

Esta seção dedica-se a apresentar os aspectos teóricos fundamentais para o desenvolvimento deste artigo, relacionados com a área da tecnologia, do ambiente virtual de aprendizagem e da educação. Nesse contexto, esta seção está organizada do seguinte modo: inicia-se com uma reflexão sobre a teoria de aprendizagem construtivista; em seguida discutese a formação em tecnologia e o novo papel do professor; logo, descreve-se a importância das tecnologias de informação e comunicação, finalizando com a apresentação do ambiente virtual de aprendizagem, bem como, do MOODLE didático.

\subsection{A teoria de aprendizagem construtivista}

Parte-se do referencial da Teoria Construtivista proposta por Jean Piaget (1977) que explica o desenvolvimento da aprendizagem e ressalta que as mudanças cognitivas resultam de um processo de desenvolvimento, onde ocorrem sucessivas mudanças qualitativas das estruturas cognitivas (esquemas) ${ }^{4}$. Cada estrutura e sua respectiva mudança derivam da estrutura precedente, de maneira gradual e nunca abrupta os esquemas são construídos e reconstruídos (MORAES, 1996; BECKER, 1999).

Existem três modelos para representar a relação do ensino e aprendizagem, antes de aprofundar-se a pedagogia relacional, que tem a construção do conhecimento proveniente das interações e ações do sujeito sobre o meio, além das adaptações da sua estrutura cerebral frente aos novos conhecimentos, o seu cerne. Mencionar-se-á duas correntes epistemológicas, empirista e apriorista, que ainda são muito utilizados nas escolas conforme refere Becker (1999).

A Pedagogia Diretiva considera que indivíduo, ao nascer, nada tem em termos de conhecimento. O docente que atua nesta corrente epistemológica chamada de Empirista considera que o conhecimento (conteúdo) deve ser depositado sobre o aluno, e sua capacidade de conhecer provém do meio físico e/ou social. Há a valorização dos sentidos, pois por eles é que entra o conhecimento, razão pela qual docentes que seguem essa pedagogia diretiva incomodam-se com o barulho (BECKER, 1992, 1999).

$\mathrm{Na}$ Pedagogia Não-diretiva a corrente epistemológica que subjaz essa pedagogia é "Apriorista", o termo designa aquilo que vem antes, como condição para o que virá

\footnotetext{
${ }^{4}$ Esquemas são estruturas mentais ou cognitivas (BECKER, 1992).
} 


\section{\#tear}

posteriormente. Nesse caso, exalta-se a bagagem hereditária, que vem antes; segundo a teoria apriorista, o ser humano nasce com o conhecimento instaurado na sua herança genética, bastando o crescimento natural para a inteligência se desenvolver. Nesta epistemologia a interferência do meio físico ou social precisa ser reduzida ao mínimo para que haja o conhecimento (BECKER, 1992, 1999).

A acepção do termo construtivismo reforça o entendimento de que nada, está pronto ou acabado, e de que, especificamente, o conhecimento não é dado, em nenhuma instância, como algo terminado. O conhecimento se concebe com a interação do sujeito com o meio físico e social, também pela importância a ele imposta pelo homem, assim como pela sua representação mental e por suas relações sociais. Para Piaget (1977) a ação ocorre antes da organização cerebral, reforça ainda que antes da ação não há pensamento. As estruturas do pensamento descritas por Piaget são classificadas em assimilação ${ }^{5}$ e acomodação $^{6}$ as quais ocorrem por sucessivas mudanças e adaptações da estrutura cerebral, provindas do processo de ação e abstração presentes no ser humano (BECKER, 1992, 1999). Reforça-se que, os conceitos aqui apresentados possibilitam uma pequena apropriação e reflexão sobre o tema, considerando que a obra de Jean Piaget sugere um maior aprofundamento.

Segundo Piaget, não se pode exaltar a importância do meio social, nem da bagagem hereditária e, a respeito desta segunda, o autor condena a crença de que a mesma já traz em si as estruturas do conhecimento, segundo a qual, bastaria o processo de maturação para estes instrumentos manifestarem-se em idades esperadas, por meio de estágios cronologicamente fixos. (BECKER, 1992, 1999).

Partindo da Pedagogia Relacional proposta por Piaget (BECKER, 1992, 1999) e conectando-a com os recursos tecnológicos, entende-se que não basta a existência de tais tecnologias agindo sobre o sujeito para que se consiga manipular e dominar determinados conhecimentos.

Corroborando com o descrito, Behar (2013) discute as possíveis relações entre a noção de competência educacional com a teoria de Piaget, na qual reforça o papel preponderante da ação para o desenvolvimento da inteligência. Nesse sentido, trazem-se as considerações de Becker (1999) a respeito da teoria de Piaget sobre o conhecimento:

\footnotetext{
5 Assimilação é um processo cognitivo pelo qual uma pessoa classifica um novo dado perceptual, motor ou conceitual às estruturas cognitivas prévias (BECKER, 1992).

${ }^{6}$ Acomodação toda modificação dos esquemas de assimilação sob influência de situações exteriores (BECKER, 1992).
} 
O conhecimento tem início quando o recém-nascido age assimilando alguma coisa do meio físico ou social. Este conteúdo assimilado, ao entrar no mundo do sujeito, provoca, aí, perturbações, pois traz consigo algo novo para o qual a estrutura assimiladora não tem instrumento (BECKER, 1999, p.8).

Convém ressaltar, que as ferramentas tecnológicas, para muitos docentes, significa algo novo. Ainda, associando a pedagogia relacional com a possibilidade de uso de objetos de aprendizagem propostos no AVA MOODLE, pode-se considerar que um único contato do professor e do aluno com a tecnologia ou objeto de aprendizagem não gera os princípios de assimilação e acomodação propostos por Piaget. Observa-se que ainda vigora em nossa educação um processo de transmissão de conhecimento e que, logo após provas e testes os conteúdos são esquecidos, ou seja, os conhecimentos não foram acomodados às estruturas cognitivas.

Nas práticas educacionais deve-se priorizar esse processo contínuo de aprendizagem, a fim de se promover o maior número de experiências no cotidiano escolar. Desse modo, percebe-se que, aprender a utilizar a tecnologia é relevante para o desenvolvimento cognitivo do aluno, além de oferecer motivação extra para sua aprendizagem (GABRIEL, 2013).

\subsection{As Tecnologias de Informação e Comunicação}

As Tecnologias da Informação e Comunicação (TICs) podem ser definidas como uma área que utiliza ferramentas tecnológicas, ou como um conjunto de recursos tecnológicos, utilizados de forma integrada, com um objetivo comum. Está presente em várias áreas: na indústria através do processo de automação; no comércio, no gerenciamento, nas diversas formas de publicidade; no setor de investimentos, através da informação simultânea e comunicação imediata; na educação, no processo de ensino e aprendizagem. As tecnologias interferem e mediam os processos informacionais e comunicativos dos seres humanos. (MORAN, 2000, 2003).

$\mathrm{Na}$ educação as primeiras tecnologias utilizadas foram o quadro negro e o livro didático. O rádio e a televisão vieram depois como forma de comunicação e também inseridos no ensino. Após a segunda metade do século 20, surgiu o computador, o Compact Disk (CD), a internet, o datashow e os cursos online (à distância), além disso, as Universidades implantaram o Campus Virtual de Ensino. (MORAN, 2003, VALENTE, 1993). 


\section{\#tear}

Em meados do ano 2000 tem-se uma intensificação dos avanços tecnológicos, inserese o conceito de Web 1.0, onde as informações eram acessadas da mesma forma que nos meios de comunicação tradicionais, assim como em um jornal, as informações eram consultadas uma de cada vez. Um site com formato de Web 1.0 é estático sem interatividade entre os usuários. Com o advento da Web 2.0, é proposta uma mudança, devido ao aumento da banda larga, foi possível acessar informações em tempo real e com diversidades de formatos como: imagens, áudio, vídeos, serviços interativos de comunicação. (BEHAR, 2013).

O termo Web 2.0 foi utilizado para demonstrar o papel ativo do usuário, que passou também armazenar, organizar e difundir as informações; em 2004 entende-se que a Web 2.0 é a rede como plataforma digital. Assim, novas ferramentas foram disponibilizadas, as informações não ficam armazenadas em programas. Para Behar (2013, p. 65), surge o conceito de "computação nas nuvens, onde já não é mais necessário instalar software nos computadores [...], o acesso aos programas se dá diretamente na internet, sendo possível editar, acrescentar, compartilhar e salvar diferentes tipos de arquivos".

Com foco na educação a distância, Behar (2013) divide as tecnologias em três tipos, sendo eles: o Ambiente Virtual de Aprendizagem (AVA), os Objetos de Aprendizagem (OA) e as ferramentas de autoria. Entende-se que AVA MOODLE, assim como os objetos de aprendizagem propostos, vão ao encontro da criação de conteúdos digitais pelos docentes. Este assunto será abordado na seção 2.4. Dessa forma, reforça-se a necessidade de formações, assunto abordado na próxima seção.

\subsection{Formação em tecnologia}

Algumas iniciativas propostas pelo governo, através de leis e programas que implantam a informática na Educação como o Proinfo $^{7}$, possibilitou um impulso à informatização das escolas, bem como, a criação de cursos de formação inicial e continuadas voltadas às tecnologias, além disso, houve o aparelhamento de salas ou Laboratórios de Informática.

Essas iniciativas, contudo, não suprem as necessidades de atualizações constantes do professor, pois se entende que também é seu papel incluir o aluno no contexto tecnológico,

\footnotetext{
${ }^{7}$ Programa Nacional de Informática na Educação (PROINFO): promoção do uso pedagógico da Informática da rede pública de ensino fundamental e médio. Disponível em: http://portal.mec.gov.br/proinfo/proinfo. Acesso: 20 de junho 2017.
} 


\section{\#tear}

pautando-se em ações que englobam o desenvolvimento físico, mental e social, quer seja na escola, na cultura, no lazer, ou no trabalho.

No que tange à dinamização das relações obtidas com a internet, há indícios de que ela rompe com a educação tradicional onde há transmissão de conteúdo, pois, segundo Carli (2013, p.25):

[...] a ideia de uma educação tradicional têm tido seus limites rompidos por novas modalidades de relações tendo na internet possível perspectiva para o professor ampliar as formas de lecionar, modificar o processo de avaliação e de comunicação com o aluno e os colegas [...].

Nesse sentido, o professor, que antes era visto como transmissor do conhecimento, agora, torna-se mediador, função esta que encerra o repasse do conteúdo e prima pela mudança no modo de ensinar, na qual o foco encontra-se na cooperação (GABRIEL, 2013).

Além disso, atualmente, com a informação disponível a um clique de distância (VEEN, VRAKKING, 2009), faz-se imprescindível a utilização das novas tecnologias em sala de aula, de forma que, aos educandos, seja proporcionada uma preparação para as novas exigências sociais e profissionais.

Segundo pesquisa ${ }^{8}$ CETIC.br (2016), em estudo realizado nas escolas brasileiras, identificou-se uma diversidade de graus de habilidade tecnológica dos professores entre 2011 e 2013. Os pesquisadores demonstraram que em algumas escolas os docentes apresentaram limitações para acessar e-mail ou para gravar um arquivo sem ajuda. Outras dificuldades foram salientadas, com a pesquisa qualitativa, referindo que os professores não conseguiam incorporar as TIC em suas atividades didáticas, bem como, não utilizavam um editor de texto, nem faziam apresentações em datashow ou pesquisas de conteúdos na internet, por exemplo.

Neste contexto é preciso propor formações voltadas à integração dos conteúdos didáticos às novas tecnologias, visando à construção do conhecimento, como modo de envolver professor e aluno na aprendizagem.

\subsection{Objetos de aprendizagem e o MOODLE}

Os conceitos de Objetos de Aprendizagem (OA) envolvem recursos que auxiliam na aprendizagem como vídeo, imagem, áudio, texto, gráfico, tabela, tutorial, aplicação, mapa,

\footnotetext{
${ }^{8}$ CETIC.br Centro Regional de Estudos para o Desenvolvimento da Sociedade da Informação do Brasil http://cetic.br/noticia/cetic-br-publica-estudo-qualitativo-sobre-uso-de-tecnologia-em-escolas-publicasbrasileiras
} 
jogo educacional, animação, infográfico e página Web (SCHMITT et al 2013).

Behar (2013) apresenta a classificação dos OA em simples (planilhas, textos e imagens), intermediário (vídeos, sites, áudio, música e apresentações) e complexo (portais, sites interativos, simulação e animação). Para a autora, os OA simples precisam de pouca interação do usuário com o objeto. Considera-se ainda que, “os intermediários têm interação limitada, já os complexos contribuem para maior interação e interatividade do usuário com o objeto" (BEHAR, 2013, p 63).

No cenário educativo, os autores reforçam o conceito de objetos de aprendizagem como: "qualquer recurso tecnológico que possa assistir a aprendizagem, atingindo um objetivo de ensino e tornando-se uma unidade de aprendizagem" (DAMACENO; SANTOS, 2013, p.5). Desse modo, entende-se sua utilização como um recurso para apoiar a aprendizagem e garantir a finalidade educacional.

Corroborando com este conceito, Bertagnolli e Valim (2012) mencionam uma utilização dos OA na qual o foco não seja apenas o conteúdo, entretanto, ao propor o uso dos mesmos na prática pedagógica, necessita-se um aprofundamento e estabelecimentos de vínculos com a disciplina, conteúdo e aprendizagem.

Como forma de ampliar o uso dos OA, algumas instituições os disponibilizam através de repositórios, os quais utilizam padrões para viabilizar buscas e o registro dos objetos nestes ambientes (BEHAR, 2013).

Existem diversos tipos de ambientes virtuais de aprendizagem AVA, além do MOODLE, como nos relembra Behar (2013), entre eles, Blackboard, Sakai, Teleduc, Solar, ROODA, Planeta ROODA, NAVi, Edx, Coursera e Claroline. Contudo, sendo o MOODLE utilizado pelo IFRS, para este artigo, não serão averiguados os outros ambientes citados.

Conforme Behar (2013) e Tarouco (2014) os ambientes virtuais de aprendizagem são locais na internet destinados à sistematização de cursos e disciplinas, além de possibilitar o monitoramento de alunos nas modalidades presencial, semipresencial (blended learning) e a distância (e-learning). Contemplam ainda o assessoramento de conteúdos de estudo, sendo assim, reforçados pela capacidade de transformação no ensino e na aprendizagem. Assim, a escolha por desenvolver o curso no MOODLE reforça-se por ser um ambiente de aprendizagem dinâmico orientado a objetos modular, ou seja, dividido em módulos (BEHAR, 2013).

Com relação a sua apresentação, trata-se de um software livre de apoio à 


\section{\#tear}

aprendizagem, executado num ambiente virtual, acessível através da internet ou de rede local, com o suporte do tutor ou professor (SCHMITT et al 2013).

Comporta ferramentas que dinamizam as relações de ensino e aprendizagem, aumentando o nível de interação entre alunos e tutores/professores, tais como: chat, fórum, glossário, questionário, tarefas, wiki, diário, laboratório de avaliação, pesquisa de avaliação, lição, diálogo, Hot Potatoes, SCORM/AICC ${ }^{9}$, base de dados e ferramenta externa, servindo também como um repositório (SCHMITT, 2009, 2013).

Os tipos de recursos permitem a inclusão de praticamente qualquer tipo de conteúdo da Web, apresentando-se disponível nos formatos de arquivo, conteúdo de pacote IMS, livro, página, pasta, rótulo, URL. Sendo assim, englobam uma diversidade de maneiras de disponibilizar o conhecimento e o material didático pelos professores.

O curso realizado no ambiente MOODLE permite ainda, através do chat, realizar discussão em tempo real por meio da Web, propiciando trocas de ideias e informações, além de feedback, a expressão da opinião exposta e a possibilidade de refazê-la.

O fórum é apresentado no MOODLE como uma atividade de discussão muito enriquecedora, apresentando diversos tipos de estrutura. Suas mensagens podem apresentar diversos formatos e permite anexar documentos.

Os participantes do fórum que realizarem assinatura no mesmo, receberão notificações de suas participações em seu e-mail e os professores podem encaminhar mensagens solicitando o envio de cópia para o e-mail de cada aluno (SCHMITT et al 2013).

Diferente do chat, o fórum permite a comunicação assíncrona dos participantes, ou seja, de acordo com sua disponibilidade pessoal, não sendo necessário que todos estejam simultaneamente conectados. A Figura 1 ilustra as ferramentas utilizadas para inserção de uma atividade.

\footnotetext{
${ }^{9}$ Padrão que permite a portabilidade de diferentes conteúdos de diversos e ambientes (SCHMITT et al 2013).
} 
Figura 1- Atividades

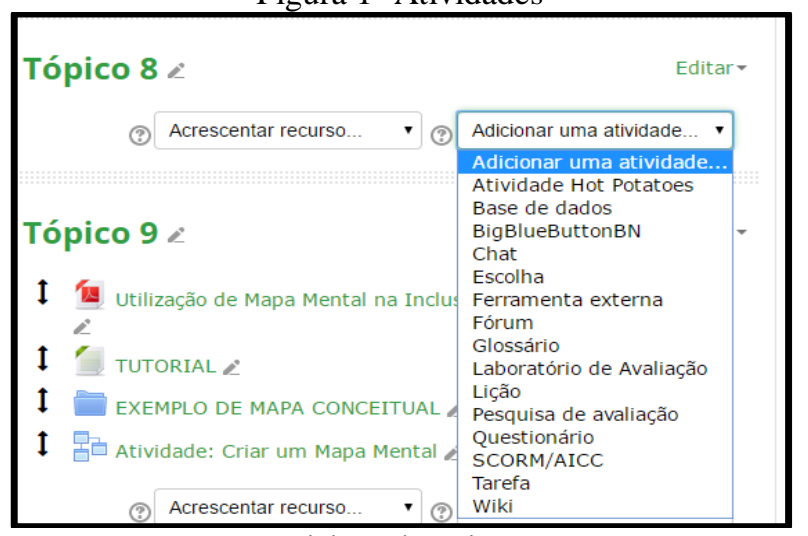

Fonte: Elaborada pelos autores

Elucidando alguns conceitos tem-se o glossário que possibilita a construção e manutenção de lista de termos ou definições, como em um dicionário, é um canal de produção coletiva. Os questionários são testes de múltiplas escolhas, verdadeiro ou falso, já a questão fechada pode fornecer feedback ao aluno (SCHMITT et al 2013).

Já a ferramenta denominada tarefa contribuiu para o professor comunicar atividades, recolher trabalhos e fornecer notas e comentários. O wiki é uma atividade que proporciona a adição e edição de uma coleção de páginas da $W e b$, de forma colaborativa ou individual, pode ser usado para trabalhos em cooperação. O diário permite ao aluno escrever sua trajetória na aprendizagem.

A ferramenta lição apresenta-se no MOODLE como um meio para o professor publicar conteúdos didáticos, pode-se utilizar um número de páginas para apresentar este conteúdo e, normalmente, indica-se uma questão com opções de respostas ao final de cada página. A escolha da resposta determina se o aluno poderá dar prosseguimento nos estudos da lição, ou se deverá permanecer na mesma página, ou ainda, voltar na página anterior para entender melhor o conteúdo que está sendo estudado (GARCIA et al 2015; SCHMITT et al 2013).

O laboratório de avaliação, ou oficina, possibilita a avaliação de trabalhos dos colegas, no qual o professor define o padrão. Por fim, a ferramenta diálogo permite conversas bidirecionais, feedbacks ao aluno e comunicação assíncrona (TAROUCO, 2014).

Foi com a evolução da internet da Web 1.0 para a Web 2.0 como citado na seção anterior, que surgiram as ferramentas de autoria. De acordo com Leffa (2006) citada em Behar (2013) é um sistema, aplicativo ou uma plataforma que viabilizam ao usuário planejar, desenvolver e confeccionar diferentes mídias, possibilitando a troca de informações entre os 
usuários. Nesse sentido, a utilização do MOODLE fortalece a cooperação entre professor e aluno na busca de um objetivo comum, a construção do conhecimento.

\section{Metodologia}

A proposta da Formação Continuada será desenvolvida na interface AVA MOODLE, pois segundo Schmitt (2013) ela permite a inclusão de objetos de aprendizagem. Destina-se a professores multidisciplinares, do $5^{\circ}$ ao $9^{\circ}$ ano do Ensino Fundamental.

Inicialmente dividiu-se em dez módulos, em que cada um apresenta um artigo abordando o assunto, um tutorial explicando o passo a passo, e uma tarefa para atividade prática com os discentes. As ferramentas de chat e fórum estarão disponíveis para interação com o Tutor (Professor) e entre aluno-aluno. As ferramentas utilizadas foram: atividade, Hot Potatoes, fórum, lição, wiki, tarefa, questionário e glossário. Os recursos que se adequaram a proposta foram arquivo, rótulo e url.

As unidades estabelecidas contemplam os seguintes conteúdos: Apresentação do curso; Tecnologias da Informação e Comunicação; Objetos de Aprendizagem; Ferramentas do Google Educação; Infográfico; História em Quadrinhos; WebQuest; Hot Potatoes; Mapa Mental e Site. A forma de certificação será pela realização com pelo menos 70\% (setenta por cento) das atividades propostas (lição, tarefa) e por concluir a avaliação no Tópico 10.

Destaca-se a finalização do projeto com um Laboratório de Avaliação, no qual o usuário teve a oportunidade de conhecer e avaliar os objetos de aprendizagem elaborados pelos colegas. A metodologia aplicada na construção do Curso de Formação, no AVA MOODLE, é exemplificada na Matriz que foi desenvolvida e apresenta-se no Apêndice A.

\section{Projeto piloto de formação}

O projeto piloto de formação foi desenvolvido no Ambiente Virtual de Aprendizagem (AVA) MOODLE $^{10}$ proporcionando o aprendizado e interação com diferentes objetos de aprendizagem. Intitulado Curso de Formação Continuada, destina-se aos professores multidisciplinares, do $5^{\circ}$ ao $9^{\circ}$ ano do Ensino Fundamental, com duração de 30h (trinta horas), dividido em 10 Tópicos. A Figura 2 demonstra a distribuição do Curso em Módulos.

\footnotetext{
${ }^{10}$ http://moodle.inf.poa.ifrs.edu.br/
} 


\section{\#tear}

Figura 2: Curso em módulos

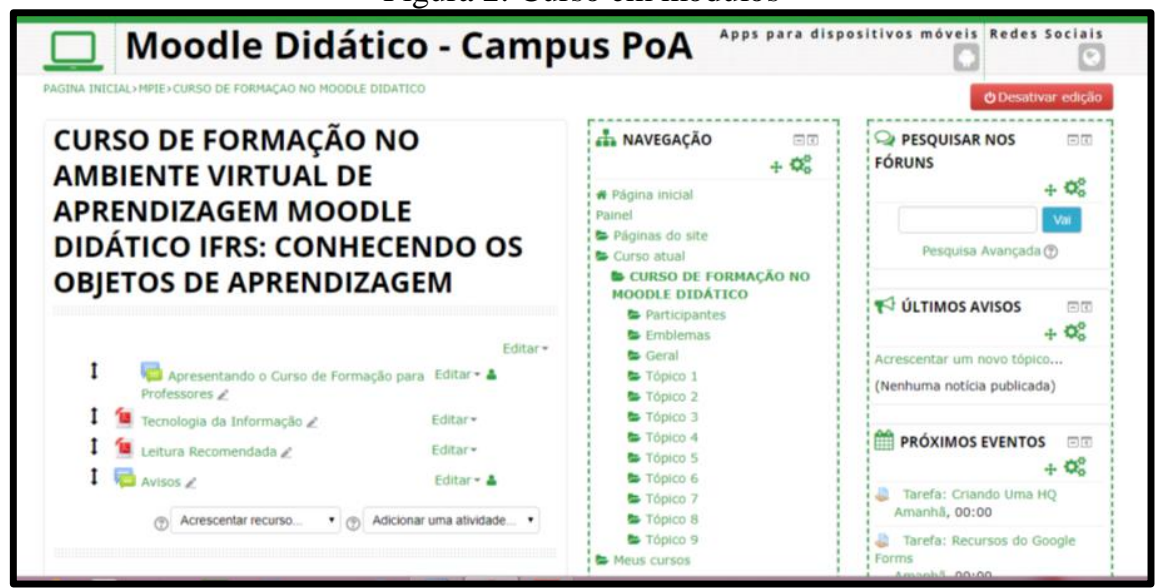

Fonte: Elaborada pelos autores.

A utilização de modo sequencial de ensino através de módulos, onde o aluno progride para o próximo módulo ao acertar, tem início em 1950 com os inventos de B. F. Skinner (VALENTE, 1993). Segundo Valente (1993), Skinner inventou uma máquina de ensinar usando o conceito de instrução programada ${ }^{11}$, entretanto ele usa um conceito no sentido de reparar, corrigir, consertar o processo de ensino. Atualmente a concepção de curso de formação em módulos trata da possibilidade de interação, colaboração entre alunos e professores, e entre alunos no ambiente virtual.

Quanto aos recursos utilizados nas atividades, inseriu-se um artigo que aborda o assunto, um tutorial explicando o passo a passo e uma tarefa para colocar a atividade em prática, conforme ilustrado nas Figuras 3 e 4.

$\mathrm{Na}$ atividade apresentada pela figura 3 tem-se plataforma Google, uma empresa internacional de serviços online e software, ao qual na parte da educação disponibiliza ferramentas gratuitas, como editor de texto, planilhas, Google Drive, Gmail (BEHAR, 2013).

\footnotetext{
${ }^{11}$ Instrução programada aplicação educacional dos conceitos desenvolvidos pelo psicólogo Skinner (Burrhus Frederic Skinner. Consiste em dividir o material a ser ensinado em módulos, ou seja, pequenos segmentos logicamente encadeados e denominados módulos. (VALENTE; 1993).
} 
Figura 3: Exemplo de atividade

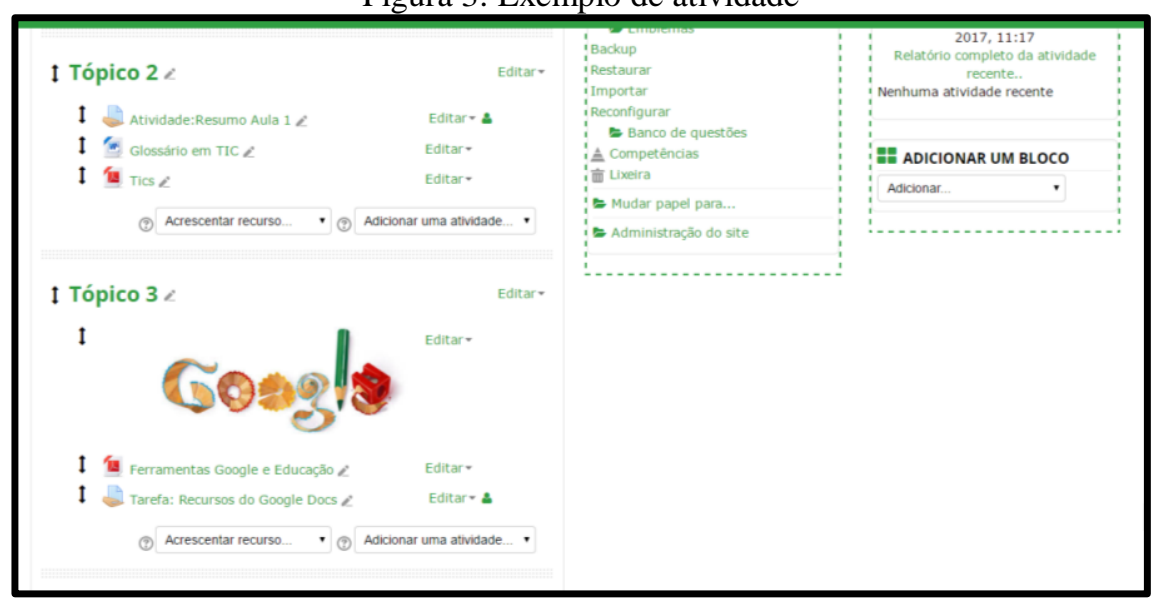

Fonte: Elaborada pelos autores.

Como material para consulta do usuário, em cada tópico desenvolvido, apresenta-se dois artigos que abordam os OA e um tutorial explicando os conceitos. A Figura 4 ilustra um exemplo da atividade com arquivos para consulta.

Figura 4: Exemplo de atividade

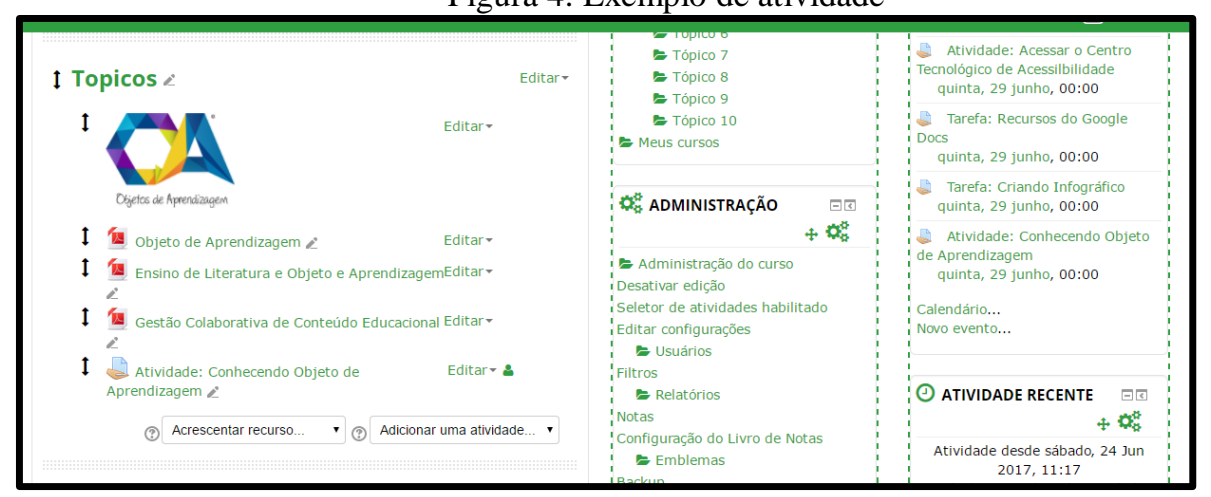

Fonte: Elaborado pelos autores.

O Hot Potatoes é um software educacional utilizado para criar atividades escolares sob a forma de objetos digitais para publicação na internet. Se usado para fins educacionais é gratuito, possibilitando a interatividade e o acesso a outros usuários. O exemplo demonstrado na figura 5 apresenta uma atividade desenvolvida com Hot Potatoes o qual mostra uma cruzadinha feita com umas das ferramentas que permitem a elaboração de atividades dinâmicas através da inserção de textos, perguntas, respostas, figuras (GUIA HOT POTATOES -UFRGS, 2017). 
Figura 5: Exemplo de atividade desenvolvida com Hot Potatoes

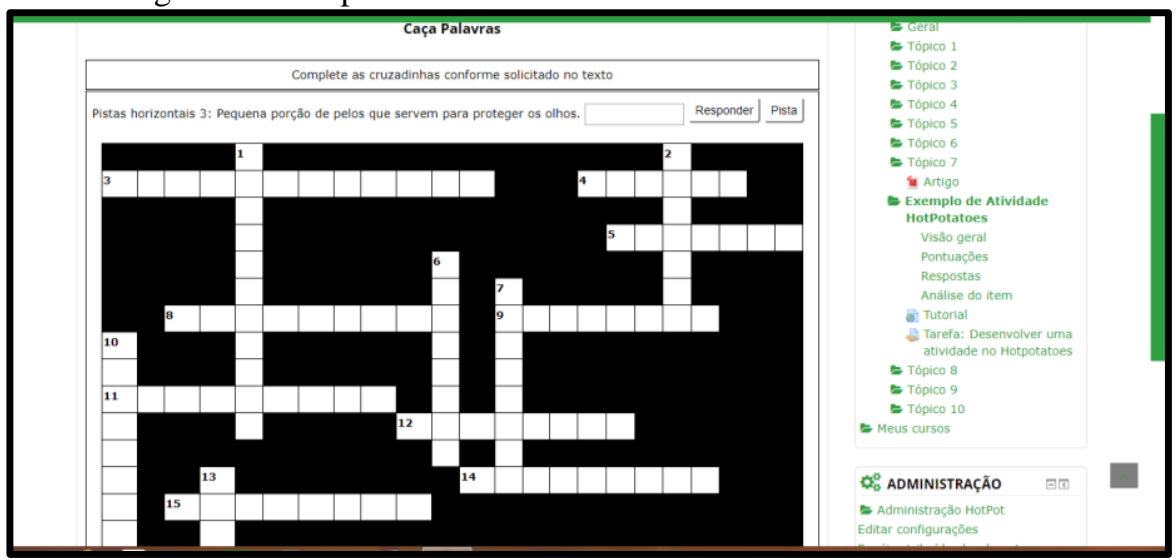

Fonte: Elaborada pelos autores

A plataforma oferece a possibilidade de inserção de ferramentas que facilitam a comunicação e inclusão de conteúdos e materiais dentro da plataforma, podemos citar: Chat, fórum, glossário, questionário, tarefas, wiki, diário, laboratório de avaliação, pesquisa de avaliação, lição, diálogo, Hot Potatoes $^{12}$, SCORM/AICC, base de dados, ferramenta externa.

\subsection{Análise dos resultados}

Em relação à proposta de inserção dos objetos de aprendizagem na plataforma MOODLE, houve a participação de todos os discentes de uma turma do Mestrado em Informática na Educação. Dentre a amostra de 17 indivíduos, somente dois não conseguiram concluir todas as atividades solicitadas.

Os resultados obtidos com a amostragem sugerem maior atenção a uma possível aplicação com professores de escolas públicas, pois se observou uma realidade diferente daquela vivenciada nas escolas. Ao participarem desta formação, os discentes tinham ao seu dispor as ferramentas necessárias, como computador atualizado e internet, a fim de poderem experienciar o uso das tecnologias; além disso, por se tratarem de alunos do Mestrado já possuíam conhecimentos prévios na área de informática, diferente do que acontece nas escolas, conforme apontado em pesquisas.

Somando-se a isso, as atividades configuraram-se num ambiente tipo "laboratório de aprendizagem", em que as condições reais foram controladas. Numa escola, obviamente, existe a presença de alunos, além dos problemas com os equipamentos, entre outras dificuldades possíveis de acontecer.

\footnotetext{
${ }^{12}$ É um programa que contém um pacote de 6 ferramentas desenvolvido por um grupo de pesquisa no Canadá. Disponível em: http://www.ufrgs.br/redespecial/_doc/guia_hotpotatoes.pdf. Acesso em jun. 2017.
} 


\section{\#tear}

Percebe-se que a inserção das TICs no ambiente escolar oportunizou novos desafios aos docentes, pois sua realidade contrasta com a dos alunos, acostumados com a utilização dos recursos tecnológicos. No entanto, Moran (2000) alerta para o fato de que o campo da educação está muito pressionado por mudanças, assim, é importante pensar em estratégias que possibilitem aprendizagens significativas em sala de aula. Nesse sentido, Tijiboy (2001, p. 53) afirma que "na era digital a construção do conhecimento deve ser coletiva", logo, infere-se que esta é uma era na qual o ensinar é complexo e requer considerável formação.

\section{Considerações finais}

O presente trabalho apresentou um projeto piloto de formação docente validado com uma turma de Mestrado Profissional em Informática na Educação, em que a aplicação ocorreu durante as aulas, apresentando como resultado uma adesão de $100 \%$ e interesse por parte dos alunos do mestrado. Reforça-se que esse é um projeto que pode ser aplicado com docentes que tenham interesse em utilizar a tecnologia em suas aulas, contribuindo para a atualização dos mesmos.

A utilização das tecnologias de informação e comunicação vem ganhando força no ambiente escolar, e em diversos setores, nos quais se faz presente a interação entre as pessoas. Observa-se que a educação, mediada pelas tecnologias, reflete essa mudança, tornando-se cada vez mais necessária no processo de ensino, como forma de incentivar a participação e cooperação entre alunos e docentes.

Dessa forma, a escolha pela utilização do AVA MOODLE propiciou não apenas o contato com diferentes objetos de aprendizagem, tais como história em quadrinhos, Hot Potatoes, WebQuest, Google Forms; mas a aquisição de conhecimentos de como utilizar tais recursos. Além disso, observou-se a participação ativa dos discentes do mestrado pelas postagens das tarefas na plataforma, observando-se a interação e a cooperação entre os pares.

Salienta-se, conforme referencial teórico, a necessidade de formações para os professores da rede pública apropriarem-se das tecnologias, pois, segundo pesquisas, uma parcela de professores que estão nas salas de aula, atualmente, recebeu sua formação quando não constava em seus currículos a abordagem das TICs (CETIC, 2016). Percebe-se que o oferecimento de um curso de formação à distância no AVA MOODLE com tutoria e espaço para reflexão da práxis, pode proporcionar, além do contato destes docentes com as TICs, a possibilidade de um planejamento pedagógico integrado aos objetos de aprendizagem, 
contribuindo, dessa forma, para a inserção das tecnologias no ambiente escolar, assim como, para o incentivo da autoria.

\title{
PROJECT PILOT OF TRAINING IN THE VIRTUAL ENVIRONMENT OF LEARNING MOODLE DIDÁTICO IFRS: GETTING TO KNOW THE LEARNING OBJECTS
}

\begin{abstract}
This article presents the construction of a pilot project of continuous training for teachers of the final years of elementary school, with the objective of analyzing the capacity of the MOODLE platform for the insertion of learning objects. Its development and evaluation took place through a discipline directed to the students of the Master of Science in Information Technology of the Instituto Federal do Rio Grande do Sul, in which it was verified that the platform presents capacity to receive different objects of learning. In addition, this environment offers the opportunity to follow the course by the tutors, encouraging the students to reflect on the use of the technologies together with the didactic contents.
\end{abstract}

Keywords: Education. Training. Technology.

\section{Referências}

BECKER, Fernando. O Sujeito do Conhecimento - Contribuições da Epistemologia Genética. Educação e Realidade, Porto Alegre, v. 24, n. 1, p. 73-88, 1999.

BECKER, Fernando. Que é Construtivismo? Revista de Educação. AEC, Brasília, DF, v. 21, n. 83, p. 7-15, 1992.

BEHAR, Patrícia Alejandra. Competências em educação à distância. Porto Alegre, Penso, 2013, 312 p.

BERTAGNOLLI, Silvia de Castro; MELO, Cimara Valim de. Ensino de Literatura e Objetos de Aprendizagem: Uma Proposta Interacionista. \#Tear: Revista de Educação Ciência e Tecnologia, Canoas, v.1, n.1, 2012.

CETIC. Pesquisa educação e tecnologias no Brasil: um estudo de caso longitudinal sobre o uso das tecnologias de informação e comunicação em 12 escolas públicas. São Paulo: Comitê Gestor da Internet no Brasil, 2016. Disponível em:

<http://cetic.br/media/docs/publicacoes/7/EstudoSetorialNICbrTICEducacao.pdf > Acesso: 01 jun.2018.

DAMACENO, Daniel Ventura; SANTOS, Rosimeire Martins Régis dos. Objeto de Aprendizagem no Contexto Escolar. \#Tear: Revista de Educação Ciência e Tecnologia, Canoas, v.2, n.2, 2013.

CARLI, Andréa de. Efeitos da Introdução das TICs no Ensino de Ciências na Educação 
Básica. Dissertação de Mestrado. UFRGS. Porto Alegre, 2013. 72 f. Orientador (a): Rochele de Quadro Loquercio.

GABRIEL, Martha. Educ@r. São Paulo: Saraiva, 2013.

GUIA HOT POTATOES. Programa que contém um pacote de 6 ferramentas desenvolvido por um grupo de pesquisa no Canadá. Disponível em:

<http://www.ufrgs.br/redespecial/_doc/guia_hotpotatoes.pdf>. Acesso em: 01 jun. 2017.

MORAES, M. A. C;. Professor e Construtivismo Piagetiano: para além de uma lógica da exclusão. Caderno de Pedagogia, Porto Alegre, n.1, 1996.

MORAN, José. Mudar a Forma de Ensinar e de Aprender - Transformar as aulas em pesquisa e comunicação presencial-virtual. Revista Interações, São Paulo, 2000. Vol. 5, p.57-72.

MORAN, José Manuel. Gestão inovadora da escola com tecnologias. Gestão educacional e tecnologia. São Paulo: Avercamp, p. 151-164, 2003.

PIAGET, Jean. Para Onde Vai a Educação? Tradução Ivete Braga, 5.ed. Rio de Janeiro: Ed. José Olympio, 1977. 96p.

PROINFO - Programa Nacional de Tecnologia Educacional. Disponível em:

<http://portal.mec.gov.br/proinfo/proinfo>. Acesso: 20 de junho 2107.

SCHMITT, Marcelo Augusto Rauh; TAROUCO Liane Margarida Rockenbach, Rodrigues Alessandra Pereira; VIDEIRA, Jonathan Alba. Depósito de objetos de aprendizagem em repositórios a partir da integração com ambientes virtuais de aprendizagem. CINTED-UFRGS, Novas Tecnologias na Educação. v. 11, n.3, dezembro, 2013.

SCHMITT, Marcelo Augusto Rauh; TAROUCO Liane Margarida Rockenbach, Rodrigues, Alessandra Pereira; VICCARI, Rosa Maria. Gestão colaborativa de conteúdo educacional. CINTED-UFRGS. V.7, n.1, Jul. 2009.

TAROUCO, Liane Margarida Rockenbach et al (Org.). Objetos de Aprendizagem: teoria e prática. CINTED-UFRGS Porto Alegre: Evangraf, 2014, 504 p.

TIJIBOY, Ana Vilma. As novas tecnologias e as incertezas na educação. In: SILVA, Mozart Linhares da (Org.). Novas Tecnologias: educação e sociedade na era da informação.

Belo Horizonte: Autêntica, 2001.

VALENTE, José Armando. Diferentes Usos do Computador na Educação.

(NIEd/UNICAMP). Em Aberto, Brasília, ano 12, n.57, jan./mar. 1993.

VEEN, Win; WRAKKING, Ben. Homo Zappiens: educando na era digital. Tradução de Vinicius Figueira. Porto Alegre: Artmed, 2009.

ZUIN, Antônio, A. S. O Plano Nacional de Educação e as Tecnologias da Informação e Comunicação. Educ. Soc., Campinas, v. 31, n. 112, p. 961-980, jul.-set. 2010. Disponível 
em: <http://www.cedes.unicamp.br>. Acesso em 01 jun.2018.

APÊNDICE A- PROTÓTIPO DE FORMAÇÃO NO AVA MOODLE.

\begin{tabular}{|c|c|c|c|c|c|c|c|}
\hline Unidade & Objetivos & Papéis & Atividades & $\begin{array}{l}\text { Duração } \\
\text { e período }\end{array}$ & Ferramentas & Conteúdos & Avaliação \\
\hline $\begin{array}{l}\text { Apresentando } \\
\text { o curso de } \\
\text { Formação } \\
\text { para } \\
\text { professores }\end{array}$ & $\begin{array}{l}\text { Ambientar } \\
\text { o aluno } \\
\text { com o } \\
\text { AVA } \\
\text { MOODLE }\end{array}$ & $\begin{array}{l}\text { Tutor e } \\
\text { aluno }\end{array}$ & $\begin{array}{l}\text { Apresentaçã } \\
\text { o } \\
\text { e vídeo }\end{array}$ & $2 \mathrm{~h}$ & $\begin{array}{l}\text { Avisos } \\
\text { Fórum } \\
\text { Vídeo }\end{array}$ & $\begin{array}{l}\text { Leituras } \\
\text { em } \\
\text { arquivos } \\
\text { PDF sobre } \\
\text { o assunto }\end{array}$ & $\begin{array}{l}\text { Realização } \\
\text { de } 70 \% \text { das } \\
\text { atividades } \\
\text { do curso e } \\
\text { concluir a } \\
\text { tarefa de } \\
\text { avaliação } \\
\text { no tópico } \\
10\end{array}$ \\
\hline $\begin{array}{l}\text { Tópico 1 } \\
\text { Tecnologias } \\
\text { da } \\
\text { Informação } \\
\text { e } \\
\text { Comunicação }\end{array}$ & $\begin{array}{l}\text { Conhecer } \\
\text { algumas } \\
\text { ferramentas } \\
\text { tecnológica } \\
\text { s e } \\
\text { compreend } \\
\text { er o } \\
\text { conceito e } \\
\text { qual a } \\
\text { importância } \\
\text { das TICs na } \\
\text { educação }\end{array}$ & $\begin{array}{l}\text { Tutor e } \\
\text { aluno }\end{array}$ & $\begin{array}{l}\text { Estratégias } \\
\text { de } \\
\text { elaboração: } \\
\text { Resumos. }\end{array}$ & $3 \mathrm{~h}$ & $\begin{array}{l}\text { Vídeo } \\
\text { Tarefa }\end{array}$ & $\begin{array}{l}\text { Leituras } \\
\text { em } \\
\text { arquivos } \\
\text { PDF e } \\
\text { Word } \\
\text { sobre o } \\
\text { assunto }\end{array}$ & \\
\hline $\begin{array}{l}\text { Tópico } 2 \\
\text { Objetos } \\
\text { de } \\
\text { Aprendizage } \\
\text { m }\end{array}$ & $\begin{array}{l}\text { Oportunizar } \\
\text { o contato } \\
\text { com novos } \\
\text { recursos } \\
\text { tecnológico } \\
\text { s }\end{array}$ & $\begin{array}{l}\text { Tutor } \\
\text { e aluno }\end{array}$ & $\begin{array}{l}\text { Pesquisa de } \\
\text { O.A. } \\
\text { existentes }\end{array}$ & $3 \mathrm{~h}$ & $\begin{array}{l}\text { Atividade } \\
\text { Fórum }\end{array}$ & $\begin{array}{l}\text { Leituras } \\
\text { em } \\
\text { arquivos } \\
\text { PDF sobre } \\
\text { o assunto }\end{array}$ & \\
\hline $\begin{array}{l}\text { Tópico 3 } \\
\text { Ferramentas } \\
\text { do } \\
\text { Google } \\
\text { Educação }\end{array}$ & $\begin{array}{l}\text { Estimular o } \\
\text { uso de } \\
\text { tecnologia } \\
\text { acessível e } \\
\text { gratuita } \\
\text { oportunizad } \\
\text { a pelo } \\
\text { Google }\end{array}$ & $\begin{array}{l}\text { Tutor } \\
\text { e } \\
\text { aluno }\end{array}$ & $\begin{array}{l}\text { Criar um } \\
\text { formulário } \\
\text { no Google } \\
\text { Forms }\end{array}$ & $3 \mathrm{~h}$ & Tarefa & $\begin{array}{l}\text { Leituras } \\
\text { em } \\
\text { arquivos } \\
\text { PDF sobre } \\
\text { o assunto e } \\
\text { tutorial }\end{array}$ & \\
\hline $\begin{array}{l}\text { Tópico } 4 \\
\text { Infográfico }\end{array}$ & $\begin{array}{l}\text { Estimular o } \\
\text { uso de } \\
\text { representaç } \\
\text { ões } \\
\text { visuais, } \\
\text { tornando as } \\
\text { informaçõe } \\
\text { s menos } \\
\text { complexas. }\end{array}$ & $\begin{array}{l}\text { Tutor } \\
\text { e aluno }\end{array}$ & $\begin{array}{l}\text { Criar um } \\
\text { infográfico } \\
\text { conforme a } \\
\text { área de } \\
\text { atuação }\end{array}$ & $3 \mathrm{~h}$ & Tarefa & $\begin{array}{l}\text { Leituras } \\
\text { em } \\
\text { arquivos } \\
\text { PDF sobre } \\
\text { o assunto e } \\
\text { tutorial }\end{array}$ & \\
\hline $\begin{array}{l}\text { Tópico } 5 \\
\text { História em } \\
\text { Quadrinhos }\end{array}$ & $\begin{array}{l}\text { Compreend } \\
\text { er o papel } \\
\text { da HQ no }\end{array}$ & $\begin{array}{l}\text { Tutor } \\
\text { e } \\
\text { aluno }\end{array}$ & $\begin{array}{l}\text { Criar uma } \\
\text { HQ } \\
\text { relacionando }\end{array}$ & $3 \mathrm{~h}$ & Tarefa & $\begin{array}{l}\text { Leituras } \\
\text { em } \\
\text { arquivos }\end{array}$ & \\
\hline
\end{tabular}




\begin{tabular}{|c|c|c|c|c|c|c|}
\hline$(\mathrm{HQ})$ & $\begin{array}{l}\text { contexto } \\
\text { escolar. }\end{array}$ & & $\begin{array}{l}\text { com uma } \\
\text { disciplina }\end{array}$ & & & $\begin{array}{l}\text { PDF sobre } \\
\text { o assunto e } \\
\text { tutorial }\end{array}$ \\
\hline $\begin{array}{l}\text { Tópico } 6 \\
\text { WebQuest }\end{array}$ & $\begin{array}{l}\text { Utilizar a } \\
\text { internet na } \\
\text { educação, } \\
\text { buscando } \\
\text { na Web. }\end{array}$ & $\begin{array}{l}\text { Tutor } \\
\mathrm{e} \\
\text { aluno }\end{array}$ & $\begin{array}{l}\text { Desenvolver } \\
\text { uma } \\
\text { WebQuest } \\
\text { com tema } \\
\text { livre }\end{array}$ & $3 \mathrm{~h}$ & Tarefa & $\begin{array}{l}\text { Leituras } \\
\text { em } \\
\text { arquivos } \\
\text { PDF sobre } \\
\text { o assunto e } \\
\text { tutorial }\end{array}$ \\
\hline $\begin{array}{l}\text { Tópico } 7 \\
\text { Hot } \\
\text { Potatoes }\end{array}$ & $\begin{array}{l}\text { Conhecer o } \\
\text { software } \\
\text { educacional } \\
\text { utilizado } \\
\text { para criar } \\
\text { exercícios } \\
\text { sob a forma } \\
\text { de objetos } \\
\text { digitais } \\
\text { para } \\
\text { publicação } \\
\text { na World } \\
\text { Wide Web. }\end{array}$ & $\begin{array}{l}\text { Tutor } \\
\text { e aluno }\end{array}$ & $\begin{array}{l}\text { Desenvolver } \\
\text { uma } \\
\text { atividade } \\
\text { utilizando } \\
\text { uma das } \\
\text { ferramentas } \\
\text { do software }\end{array}$ & $3 \mathrm{~h}$ & Tarefa & $\begin{array}{l}\text { Leituras } \\
\text { em } \\
\text { arquivos } \\
\text { PDF sobre } \\
\text { o assunto e } \\
\text { tutorial }\end{array}$ \\
\hline $\begin{array}{l}\text { Tópico } 8 \\
\text { Mapa Mental }\end{array}$ & $\begin{array}{l}\text { Aprender a } \\
\text { organizar as } \\
\text { tarefas e } \\
\text { ideias de } \\
\text { uma forma } \\
\text { mais } \\
\text { simples. } \\
\text { Solucionar } \\
\text { problemas } \\
\text { complexos, } \\
\text { mas que, } \\
\text { com a } \\
\text { divisão de } \\
\text { passos, } \\
\text { acabam } \\
\text { ficando } \\
\text { bem mais } \\
\text { simples. }\end{array}$ & $\begin{array}{l}\text { Tutor } \\
\text { e aluno }\end{array}$ & $\begin{array}{l}\text { Criar um } \\
\text { mapa mental }\end{array}$ & $2 \mathrm{~h}$ & Atividade & $\begin{array}{l}\text { Leituras } \\
\text { em } \\
\text { arquivos } \\
\text { PDF sobre } \\
\text { o assunto e } \\
\text { tutorial }\end{array}$ \\
\hline $\begin{array}{l}\text { Tópico } 9 \\
\text { Criando um } \\
\text { Site }\end{array}$ & $\begin{array}{l}\text { Melhorar e } \\
\text { estimular a } \\
\text { comunicaçã } \\
\text { o com } \\
\text { alunos e } \\
\text { pais, } \\
\text { publicar } \\
\text { atividades } \\
\text { de interesse } \\
\text { dos alunos. }\end{array}$ & $\begin{array}{l}\text { Tutor } \\
\text { e aluno }\end{array}$ & $\begin{array}{l}\text { Elaborar um } \\
\text { site com } \\
\text { conteúdo } \\
\text { educacional }\end{array}$ & $3 \mathrm{~h}$ & Tarefa & $\begin{array}{l}\text { Leituras } \\
\text { em } \\
\text { arquivos } \\
\text { PDF sobre } \\
\text { o assunto e } \\
\text { tutorial }\end{array}$ \\
\hline $\begin{array}{l}\text { Tópico } 10 \\
\text { Avaliação }\end{array}$ & $\begin{array}{l}\text { Avaliar a } \\
\text { proposta do } \\
\text { curso } \\
\text { quanto ao } \\
\text { uso no } \\
\text { ambiente } \\
\text { escolar }\end{array}$ & $\begin{array}{l}\text { Tutor e } \\
\text { aluno }\end{array}$ & $\begin{array}{l}\text { Avaliar dois } \\
\text { O.A. } \\
\text { segundo } \\
\text { critérios } \\
\text { específicos: } \\
\text { Conteúdo e } \\
\text { uso }\end{array}$ & $2 \mathrm{~h}$ & $\begin{array}{l}\text { Laboratório } \\
\text { de } \\
\text { Avaliação }\end{array}$ & $\begin{array}{l}\text { O.A. } \\
\text { apresentad } \\
\text { os pelos } \\
\text { colegas }\end{array}$ \\
\hline
\end{tabular}

